\title{
A Poética do Conflito na obra para dois pianos En Blanc et Noir de Claude Debussy
}

\author{
The Poetic of Conflict in the works for two \\ pianos En Blanc et Noir by Claude Debussy.
}

por Menan Medeiros Duwe e Guilherme A. Sauerbronn de Barros

\begin{abstract}
RESUMO
Essa artigo propõe uma avaliação das referências poéticas apresentadas pelo compositor francês Claude Debussy em sua obra para dois pianos composta em 1915, En Blanc et Noir, profundamente influenciada pela Primeira Guerra Mundial. A partir do artigo de Jonathan Dunsby: "The Poetry of Debussy's En blanc et noir", propomos a interpretação das referências, relacionando informações extramusicais, em três tipos de conflitos, um para cada movimento, circundando o nacionalismo que passa a ser afirmado com força ainda maior após o início da guerra. Para isso, investigaremos cartas trocadas na época que abordem o assunto junto com informações levantadas sobre o compositor, e proporemos relações com elementos da obra em questão, tanto no diz respeito ao seu conteúdo musical quanto ao textual que o compositor agrega a partitura de sua música. Isso mostrará a importância de uma abordagem desse tipo para sua compreensão, o que pode reforçar e embasar a construção de uma interpretação.
\end{abstract}

Palavras-chave Debussy; En Blanc et Noir; Poética; Conflito; Primeira Guerra

\section{ABSTRACT}

This article proposes an evaluation of the poetical references made by the French composer Claude Debussy in his work for two pianos composed in 1915, En Blanc et Noir, deeply influenced by the First World War. Based on the article by Jonathan Dunsby: "The Poetry of Debussy's En blanc et noir," we propose the interpretation of references, relating extra musical information, in three types of conflicts, one for each movement, circling the nationalism that is being asserted with even greater force after the beginning of the war. For this, we will investigate letters exchanged at that time, that approach the subject with information obtained about the composer, and propose relationships with elements of the work in question, both in terms of its musical content and the text added to the score by the composer. This shows the importance of such an approach for the understanding of his music, that can strengthen and base the construction of an interpretation.

Keywords Debussy; En Blanc et Noir; Poetic; Conflict, Fist World War 
En blanc et noir é uma obra de conflito e essa característica está incorporada no seu título, literalmente "Em Branco e Preto". Usualmente no nosso idioma falamos "preto e branco" e no francês acontece o mesmo com "noir et blanc" ou, algumas vezes, "noir sur blanc", assim como no inglês "black and white". Uma exceção foi encontrada por Dunsby no idioma em torno do xadrez, onde a luta se dá entre a rainha branca e a rainha preta, entre o cavalo branco e o cavalo preto, além de, no geral, pensarmos na luta entre "o bem e o mal" e não entre "o mal e o bem", associando comumente o primeiro ao claro e o segundo ao escuro. As palavras "em branco e preto" de Debussy seriam portanto um sinal de luta e resignação', como pretendemos mostrar nesse artigo.

Porém, os significados que devem ressoar de En blanc et noir são vastos e, provavelmente, como toda a poesia, não são finitos. Para isso devemos ver Debussy como um poeta que se "moveu tão facilmente entre palavra e som que nós podemos facilmente perder o que ele está fazendo" ${ }^{\prime 2}$. Conforme nos fala Dunsby, isso explicaria em parte porque Debussy não é totalmente compreendido, caindo em lacunas que ele mostra existir entre o Romantismo e a música a partir da Primeira Guerra, ou entre a teoria e a história, sendo sempre difícil colocá-lo em algum lugar. Os Préludes poderiam ser preparações (prelúdios em si) para a poesia de seus títulos, anunciados somente depois de criada a atmosfera pelos sons. La Mer ou Prélude à l'après-midi d'un faune, segundo Dunsby, deveriam tocar dentro da música, e não somente com ela. Os títulos na música de Debussy são parte da poesia da criação artística, sobre a qual podemos perceber características lendo uma carta a Stravinsky com uma trabalhada construção3:

Você está surpreso por eu estar chamando de Jeux e prefere 'Le Parc'! Por favor, acredite em mim, Jeux é melhor. Por um lado é mais curto; e por outro essa é uma maneira conveniente de expressar os 'horrores' que acontecem entre três participantes. ${ }^{4}$

A partir dessa breve reflexão, devemos mostrar que a compreensão dos elementos poéticos extramusicais para a obra artística de Debussy é essencial para o entendimento de En Blanc et Noir e por isso seguiremos relacionando cartas trocadas na época que abordem 0 assunto junto com informações levantadas sobre o compositor, e proporemos relações com elementos de sua música.

A referência mais imediata de En Blanc et Noir é, em todo caso, ao piano, sendo que 0 instrumento também é uma exceção na utilização linguística dessa

1 DUNSBY, Jonathan. The Poetry of Debussy's En blanc et noir. In: Analytical Strategies an Musical Interpretation. Editapo por Craig Ayrey and Mark Everist. Cambridge: Cambridge University Press, 1996. P.152. As traduções presentes nesse trabalho são de nossa autoria.

2 Ibid., p.152.

3 Ibid., pp.151-152.

4 DEDUSSY apud DUNSBY, 1996, p.152. 
dualidade por possuir as teclas majoritariamente brancas. Também pode representar a própria sonoridade da música pela coloração timbrística "reduzida" dos dois pianos: se a compararmos às possibilidades timbrísticas de uma orquestra, essa possui riqueza de variedade textural similar, mas muito mais coloração.

Sexta-feira 4 fevereiro 1916, Debussy a Godet

Traga seu cérebro para suportar En blanc et noir ... Essas peças desenham suas cores, suas emoções, simplesmente do piano, como os 'cinzas' de Velazquez, se assim posso sugerir? De qualquer modo, todos os músicos de orquestra estão no front e aqueles que foram deixados para trás - por qualquer ato da providência administrativa - são difíceis de aturar porque eles não conseguem se consolar interpretando com mau gosto [hamming] e confortavelmente a "A cavalgada das Valquírias" como de costume. ${ }^{5}$

E ainda, para reforçarmos a referência às cores, em um efeito imagético da música como um pensamento poético nessa obra, observemos uma pista deixada por Debussy ao escrever à Durand na época em que compunha, dessa vez tratando da expressividade do claro e do escuro:

14 de julho de 1915

Tenho que confessar que fiz uma ligeira mudança na coloração do segundo movimento dos caprichos (Ballada de Villon contra os inimigos da França); ele estava tão profundamente negro e quase tão trágico quanto um 'Caprice' de Goya!

En blanc et noir é composta de três peças, três "caprichos", como se refere Debussy na época, e cada uma delas seria símbolo de uma categoria de conflito. Esses caprichos, fantasias, produtos da imaginação tumultuada pelo caos em que a Europa submergira, seriam a expressão musical dos sentimentos que ele desejaria ter mais força para afirmar, como veremos adiante. Toda essa carga fica anunciada pelas epígrafes e dedicatórias que Debussy colocou em cada movimento, conforme discutiremos.

Tomaremos, portanto, a Primeira Guerra Mundial como ponto de partida. A segunda peça, que quase se tornara escura demais (ou excessivamente trágica) é sobre essa guerra, o plano de fundo para todos os conflitos que essa música apresenta. É uma investida poética contra os "inimigos da França", nesse caso, a Alemanha, que por ter criado uma situação que obrigara os músicos das melhores orquestras a ir para o front, fez com que essa obra tivesse que ser escrita em branco e preto, música para piano e não para orquestra. A partir disso, ela expressa a tortura pela qual passava o "músico francês"7 (forma como Debussy se afirmara ao publicar as sonatas que compôs nessa mesma época). Seu nacionalismo, que se construiu e

5 Ibid. p. 153 .

6 Ibid. p.153.

7 DUNSBY, p.156. 


\section{A Poética do Conflito na obra para dois pianos \\ En Blanc et Noir de Claude Debussy}

se manifestou durante toda sua produção como músico e crítico, se tornou muito forte e decidido nesse momento.

Dunsby também faz algumas considerações sobre a relação de En blanc et noir com a tecnologia emergente do cinema mudo. Avaliar se o título da obra se associa também ao cinema mudo é difícil, uma vez que Debussy não deixa essa informação. Ao criticar duramente essa pequena parte do trabalho de Dunsby, Paulin ${ }^{8}$ comenta que os filmes em "preto e branco" tinham suas películas frequentemente coloridas com tinta na época de Debussy. Contudo, somente partes selecionadas da imagem eram coloridas, registros de filmes importantes em preto e branco nos permitem ver que não é possível negar que essa tecnologia se caracterizava - apesar de certos detalhes coloridos chamarem a atenção - por uma ausência geral de cor (como se imagina comumente). A possibilidade de o cinema ter influenciado a concepção de música programática de Debussy não deve ser descartada, uma vez que ele também nunca negou a relação. Assim, acrescentamos o cinema mudo como uma referência compatível com essa música.

\section{0 espírito francês esquecido, um músico com dificuldades}

En blanc et noir é composta em um período em que Debussy buscava claramente recuperar uma música autenticamente francesa, que ele acreditava ter se perdido quando o encanto e a fineza de Rameau foram substituídos por uma maneira de conceber música unicamente pelo efeito dramático: "o 'achado' harmônico que acaricia o ouvido dará lugar à harmonia maciça..." . Poucos anos antes ele também escreveu: “(...) podemos pelo menos constatar esse fato brutal: não há mais tradição francesa"10. Se, em sua concepção nacionalista, Debussy busca ressuscitar a sutileza em uma música que seria verdadeiramente francesa em sua essência, compondo três sonatas de câmara até o final de sua vida e os estudos para piano, obras que expressam espécie de escapismo direcionada ao passado, ao simples e bucólico"1 En blanc et noir é o seu suspiro agitado na direção de seus ideais, enfrentando o mundo com sua música.

8 PAULIN, Scott D. "Cinematic" Music: Analogies, Fallacies, and the Case of Debussy. In: Music and the Moving Image, University of Illinois Press, v.3, n.1, spring 2010. P.10.

9 DEBUSSY, 1989, p.183. Novembro de 1912. 'Jean-Philippe Rameau.'

10 DEBUSSY, 1989, p.176. Le Figaro, 8 de maio de 1908. 'Sobre Hipploly et Aricie.'

11 Os títulos dos movimentos das Sonatas representam um afastamento em relação às sonatas do séc. XIX: Prologue, Sérénade (na sonata para violoncelo), Pastorale, Interlude (na sonata para flauta, viola e harpa) e Intermède (sonata para violino) eram termos usuais na música do séc. XVIII. A admiração pelos compositores franceses dessa época, Rameau e Couperin, é clara nas palavras de Debussy e é neles que o compositor encontra a essência da música francesa. 


\section{A Poética do Conflito na obra para dois pianos \\ En Blanc et Noir de Claude Debussy}

Esse nacionalismo tem relação direta com os ares de Paris na virada o século XX, quando a cidade se tornara a grande capital cultural que por vezes parecia mais interessada na música estrangeira:

Embora importantes composições de Fauré, Ravel e Debussy fossem executadas pela primeira vez na primavera e no verão de 1913, toda a comoção e excitação pareciam ser geradas por artistas e compositores estrangeiros como Strauss, Moussorgsky, Stravinsky e os ballets russos. Nesse mesmo ano, o centenário de Wagner foi festejado em Paris com representações de Tristão e Isolda e todo o ciclo do Anel dos Nibelungos. ${ }^{12}$

Quando a Alemanha declarou guerra, em 3 de agosto de 1914, trouxe à tona rivalidades acumuladas com a França que se estendem facilmente aos domínios artísticos: toda a cultura do inimigo é proibida, todas as edições alemãs são retiradas de mercado. Debussy, que já sofria os primeiros sintomas de um câncer, se esforçava para dar conta de seus compromissos financeiros, encarregando-se de fornecer revisões de Chopin (que o influenciou fortemente na composição de seus estudos) e de Bach ao seu editor, Jacques Durand. Talvez Durand tenha recebido com surpresa a carta do compositor informando-lhe do seu desejo de dedicar-se à composição dos "caprichos" para dois pianos:

30 de junho de 1915, a Durand.

Choisnel falou-me novamente das sonatas de Bach. É urgente? Tendo, neste momento, algumas idéias (não nos apressemos em iluminá-las"), gostaria de as cultivar em benefício de peças para dois pianos. ${ }^{13}$

7 de julho de 1915, a Durand.

Quando você gostaria de ouvir os Caprices en blanc et noir? ${ }^{14}$

A doença de Debussy manifestou-se pouco antes de deflagrada a guerra e the causava extremo desconforto. Tendo passado por uma cirurgia no final de 1915, Debussy morreu em 25 de março de 1918, aos 55 anos. No mesmo ano do início da guerra, ele dedicara os primeiros seis meses a viagens incessantes promovendo a sua música e a de contemporâneos, atuando como pianista e regendo orquestras em Roma, Amsterdã e Bruxelas. Ele amargava uma fase difícil: já não tão admirado pelo grande público como o fora em sua juventude, sua doença piorava com essas viagens incessantes; esforçando-se para honrar seus compromissos financeiros, as

12 BENEDETTI, Danieli. A Produção Pianística de Claude Debussy durante a Primeira Guerra Mundial. Anais de Fórum CLM 2002. São Paulo: ECA/USP, 2002b. P.109.

13 DEBUSSY apud MARTINS, Jose Eduardo. 0 Som Pianístico de Claude Debussy. São Paulo: Novas Mestas, 1982. P.192.

14 DEBUSSY apud MARTINS, p.192. 


\section{A Poética do Conflito na obra para dois pianos \\ En Blanc et Noir de Claude Debussy}

recepções pouco entusiasmadas de algumas de suas obras provocaram nele forte impressão'

Por isso trataremos a inquietude e o desconforto pessoal de Debussy como mais uma categoria de conflito expressa nessa obra. A primeira peça é uma profusão de humores que se manifesta em gestos súbitos: a música é permeada por uma atmosfera dançante que revela um desespero e por vez se torna macabra, os ambientes oníricos abrem portas para expressar o desconforto de se sentir deslocado.

\section{Do inverno ao verão}

Tendo exposto os dois primeiros conflitos, iniciaremos explorando as referências de En blanc et noir a partir do terceiro deles, que poderia ser descrito como ideológico, ou então estético, e se manifesta na sua relação com o jovem compositor Stravinsky, que foi muito seu amigo nesse período. A ele a terceira peça foi dedicada: à mon ami lgor Strawinsky.

Stravinsky e Debussy se conheceram em 1910, por ocasião da estréia de l'0iseau de feu. Por volta de 1912 passaram a se encontrar regularmente; um desses encontros inesquecíveis foi o da leitura a quatro mãos, pelos dois compositores, de Sacre du Printemps ${ }^{16}$. Para começarmos a investigar o que poderia significar essa dedicatória na ideia do conflito, verifiquemos uma preciosa carta que Debussy escreveu a esse ilustre amigo:

Paris, 24 de outubro de 1915.

Em primeiro lugar, muito querido amigo, é uma alegria ter notícias suas afinal. . . Tive algumas por seus amigos que, não sei por que, mantinham seu estado de saúde e sua residência em mistério.

Estamos indo um pouco melhor, ou, em outras palavras, estamos como a maioria do povo francês. Temos a nossa parte de tristezas, de dificuldades espirituais e domésticas. Mas isso é natural, agora que a Europa e o resto do Mundo acham necessário participar desse trágico "concerto". Por que os habitantes de Marte não se unem à luta? Como você me escreveu, "eles não serão capazes de nos fazer aderir à sua loucura". Mas mesmo assim há qualquer coisa de mais alto que a força bruta, "fechar as janelas" à beleza é contra a razão, e destrói o verdadeiro sentido da vida.

Mas devemos abrir nossos olhos e nossos ouvidos para outros sons quando o barulho dos canhões tiver cessado. 0 mundo deve se livrar

15 BENEDETTI, 2002b, pp.108-109.

16 BENEDETTI, Danieli. A Produção Pianística de Claude Debussy durante a Primeira Guerra

Mundial. Dissertação de Mestrado em Música. São Paulo: ECA/USP, 2002a.P.73. 
dessa semente ruim. Temos todos que matar os micróbios da falsa grandeza, da feiúra organizada, que nem sempre compreendíamos ser apenas fraqueza.

Você será necessário na guerra contra esses outros gases igualmente mortiferos, e contra os quais não existem máscaras.

Caro Stravinski, você é um grande artista. Seja, com toda força, um grande artista russo. É tão maravilhoso pertencermos ao nosso país, sentirmo-nos presos ao nosso solo como o mais humilde dos camponeses! E quando o estrangeiro pisa este solo, como parecem amargos todos os contra-sensos do internacionalismo.

Nesses últimos anos, quando eu respirava miasmas austro-boches na arte, desejava mais autoridade para gritar minhas preocupações, avisar dos perigos de que nos aproximávamos tão credulamente. Ninguém suspeitava que essa gente estava conspirando a destruição de nossa arte, como tinham preparado a destruição de nossas pátrias? E esse antigo ódio nacional que só terminará com o último alemão! Mas haverá algum dia um "último alemão" ? Porque estou convencido de que os soldados alemães geram novos soldados alemães.

$[\ldots]$

É preciso confessar que a música está em má situação por aqui... Serve só para fins caritativos'7, e não devemos reclamar por isso. Fiquei aqui por mais de um ano, incapaz de escrever música. Só durante os últimos três meses, passados à beira-mar com amigos, recuperei a faculdade do pensamento musical. A menos que se esteja pessoalmente envolvido nela, a guerra é um estado de espírito contrário ao pensamento. Goethe, aquele egoísta olímpico, foi o único que pôde trabalhar, dizem, no dia em que o exército francês invadiu Weimar. . . E também houve Pitágoras que foi morto por um soldado no momento em que ia resolver só Deus sabe que problema.

Recentemente não escrevi senão música pura, doze estudos para piano e duas sonatas para diferentes instrumentos, na nossa velha forma que generosamente não impôs esforços tetralógicos ${ }^{18}$ de audição. [...]

CLAUDE DEBUSSY'

Nessa carta podemos perceber os três conflitos que estamos propondo: 0 desconforto de Desbussy que o faz passar tanto tempo sem escrever, a maneira como a

17 É curioso, por parecer ter sido profetizado na carta por Debussy, que a primeira audição de En blanc et noir tenha sido em benefício de uma campanha humanitária Vêtement du Prisonnier de Guerre (roupas para prisioneiros de guerra), no dia 21 de dezembro de 1916, quando o compositor tocou com Roger Ducasse, pouco mais de um ano após a operação a que fora submetido (MARTINS, p.193).

18 Certamente uma referência à tetralogia de Richard Wagner.

19 DEBUSSY in CRAFT e STRAVINSKY, 1984, p.41. 
guerra abala enormemente a França despertando a força de seu nacionalismo, e a forte amizade com Stravinsky a quem ele transmite a sua mensagem. 0 clamor ideológico fica claro quando ele diz que deveriam estar preparados para enfrentar a "falsa grandeza" e a "feiúra organizada" quando o barulho dos canhões tivesse cessado, uma batalhada que precisaria de Stravinsky para ser travada. No mesmo ano, falando em nome de seu nacionalismo, Debussy mostra o que acreditava que deveria ser combatido:

Adotamos os procedimentos de escrita mais contrários ao nosso espírito, os exageros de linguagem menos compatíveis com nosso pensamento; sofremos as sobrecargas da orquestra, a tortura das formas, o luxo grosso e a cor espalhafatosa... e estávamos à véspera de assinar naturalizações bem mais suspeitas ainda quando o canhão pediu bruscamente a palavra! (...) a vitória deve devolver aos artistas o sentido da pureza e nobreza do sangue francês. ${ }^{20}$

Debussy não comenta sobre En blanc et noir na carta, até a omite ao citar os trabalhos aos quais estava se dedicando, nem o faz posteriormente como Stravinsky escreve em suas memórias: "Eu o vi mais ou menos nove meses antes da sua morte. Debussy não falou uma palavra a respeito da peça En blanc et noir que ele escreveu para mim". Uma pista para entender o que Debussy desejava dizer se encontra em uma Carta a Robert Codet de 1915: "Stravinsky se inclina perigosamente para o lado de Schöenberg" estar se remetendo à linguagem atonal de Schoenberg, que, de acordo com o discurso desse compositor, seria a continuação natural da música germânica. Se o estilo dessa cultura já era corrompido segundo a proposta estética de Debussy, o que ele pensaria então desse tipo de organização das alturas que estava sendo proposto?

Porém, os comentários de Debussy sobre os trabalhos de Stravisnky, dirigidos em cartas ao seu amigo, eram sempre elogiosos e admirados, e isso intrigou o compositor russo em sua entrevista:

Não creio que tenha havido mudança em Debussy em conseqüência de nosso contato. Depois de ler as cartas que me escreveu, amáveis e elogiosas (gostou muito de Petruchka), fiquei intrigado ao encontrar sentimentos bastante diferentes sobre minha música em cartas a músicos amigos, no mesmo período. Seria duplicidade, ou estaria ele aborrecido por sua incapacidade de assimilar a música de Le Sacre, quando a geração mais jovem acreditava nela entusiasticamente? É difícil de julgar agora, a uma distância de mais de quarenta anos. ${ }^{22}$

20 DEBUSSY, 1989, p.230. L'INTRANSIGEANT, 11 de março de 1915. 'Enfim, sós!...'

21 LOCKSPEISER apud BENEDETTI, 2002a, p.74

22 CRAFT E STRAVINSKY, 1984, p.36. 


\section{A Poética do Conflito na obra para dois pianos \\ En Blanc et Noir de Claude Debussy}

Possivelmente nenhuma coisa nem outra, talvez Debussy quisesse transmitir uma mensagem a esse amigo sem recorrer a acidez de um discurso direto, o que fez deixando pistas na veemência de suas ideias e na elegância de sua música. No início da terceira peça encontramos a epígrafe:

rver, vous n'este qu'um vilain... (Charles d'Orléans)

"Inverno, você não é mais que um vilão" é uma evocação sazonal que poderia transmitir - para começarmos a pensar a poética nos termos do título - o branco pela imagem da neve, relação que pode ser feita com facilidade. Porém, Debussy já havia usado o poema inteiro na terceira das Trois Chansons de Charles d'Orleans para quatro vozes misturadas não acompanhadas, que teve a primeira performance em $1909^{23}$, e o poema todo pode apresentar indícios interessantes:

Inverno, você não passa de um vilão

0 Verão é agradável e gentil

Em testemunho de maio e abril

Que o acompanham de manhã à noite

0 Verão reveste campos, bosques e flores

Com seu casaco de verdura

E de muitas outras cores

Por ordem da Natura

Mas você, Inverno, está cheio de neve, vento, chuva e granizo

Deviam bani-lo em exílio.

Sem rodeios eu the digo:

Inverno, você não passa de um vilão! ${ }^{24}$

Depois de apontarmos a importância de Stravinsky como um aliado contra o que Debussy acreditava que deveria ser combatido quando a guerra acabasse, podemos pensar então nessa guerra como o inverno, que, como toda estação, tem um

23 DUNSBY, 1996, p.156.

24 Yver, vous n'este qu'um vilain

Esté est plaisant et gentil

En temoing de may et d'auril

Qui l'accompaignent soir et main.

Esté revet champs, bois et fleurs

De sa livrée de verdure

Et de maintes autres couleurs

Par l'ordenance de nature

Mais vous, Yver, trop estes plain de nège, vent, pluye et grézil.

on vous deust banir en éxil.

Sain point flater je parle plain :

rver, vous n'este qu'um vilain 
fim, e o verão, com todas as suas sutilezas ordenadas pela natureza, suas cores, como sua inevitável antítese. Mais do que a própria guerra, esse inverno, que não passa de um vilão, poderia representar os "gases igualmente mortíferos" para os quais não se tem máscara, a apontada degeneração da arte, segundo Debussy. E quem melhor do que o seu amigo russo para entender os males do inverno e seu significado carregado!

Essa associação com o caráter passageiro das estações transmite uma perspectiva positiva sobre a situação (a clareza em oposição ao sombrio no segundo movimento?), o que combina com a indicação Scherzando no início do movimento. Afinal, é exigida certa tranqüilidade para se poder fazer brincadeiras. Dunsby sugere uma relação entre os movimentos ondulantes de notas rápidas que são abundantes nesse movimento com uma representação de vento, e nessa associação, uma melodia que sugere o tema do Pássaro de Fogo de Stravinsky seria varrida pelo soprar do inverno: na figura 1 temos o padrão do prelúdio 0 vento sobre a planície (Le vent dans la plaine) que pode ser associado com o padrão no primeiro piano do trecho mostrado na figura 2; no segundo piano temos a melodia que remete ao tema do Pássaro de Fogo, mostrado na figura 3; a figura 4 apresenta essa mesma melodia, já no final desse scherzando, com uma similaridade maior com a melodia de Stravinsky.
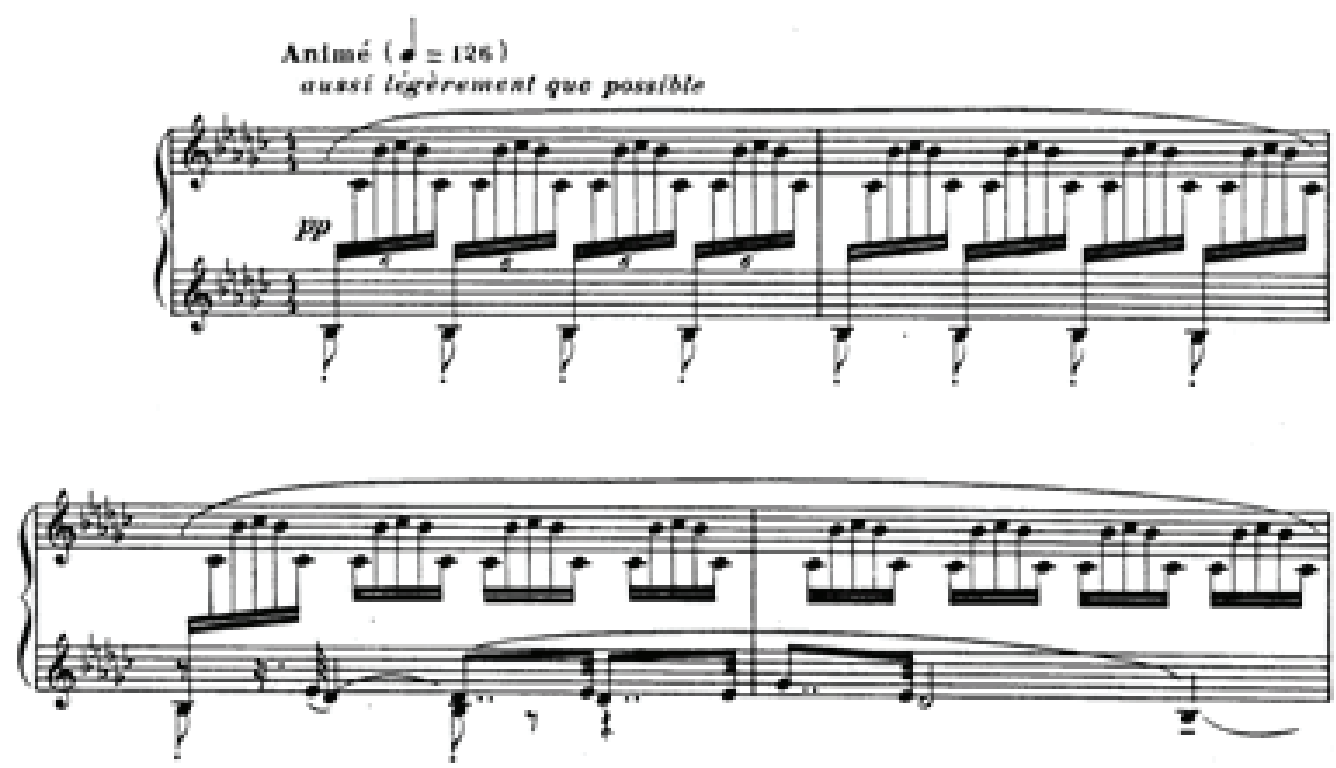

Figura 1: Le vent dans la plaine, Prèlude III, Livre I, C. $1-4^{25}$.

25 DEBUSSY, Claude. Préludes pour piano: ...Le vent dans la plaine. Paris: Durand a Cie., 1910. Pp.7-12. Disponível em 〈http://imslp.org/wiki/Pr\%C3\%Agludes_(Book_1)_(Debussy,_Claude)>Acesso em: 14 de jun. 2011. 

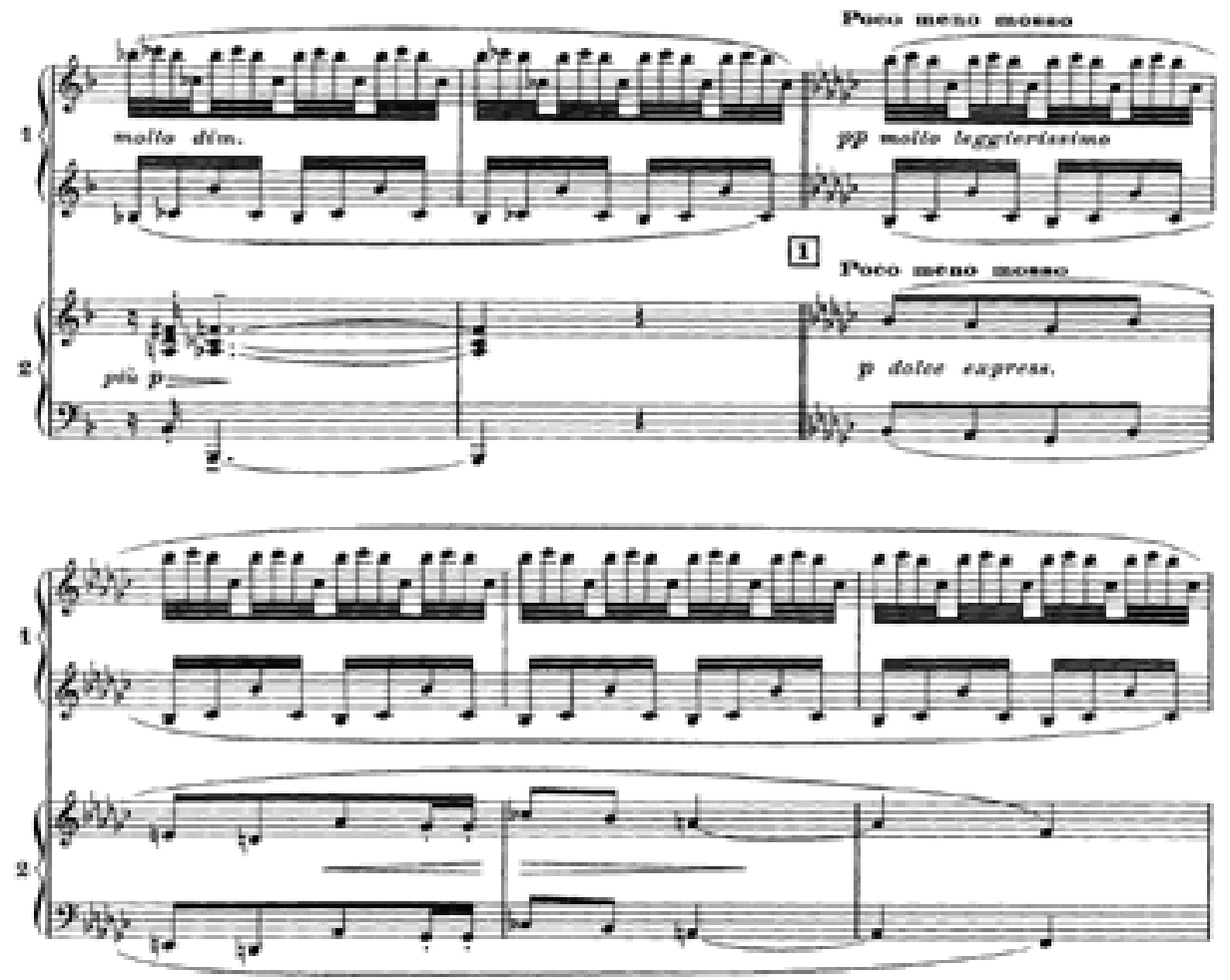

Figura 2: En blanc et noir, III, c.23-28.

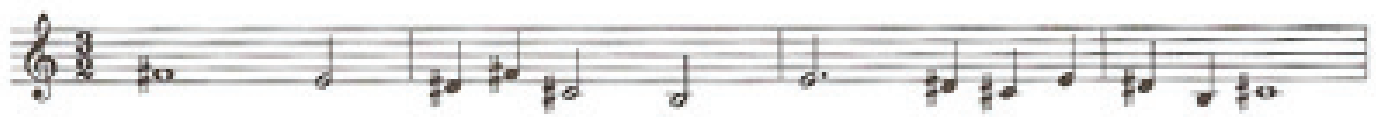

Figura 3: Stravinsky, Pássaro de Fogo, tema em Si maior. Dunsby p.159.
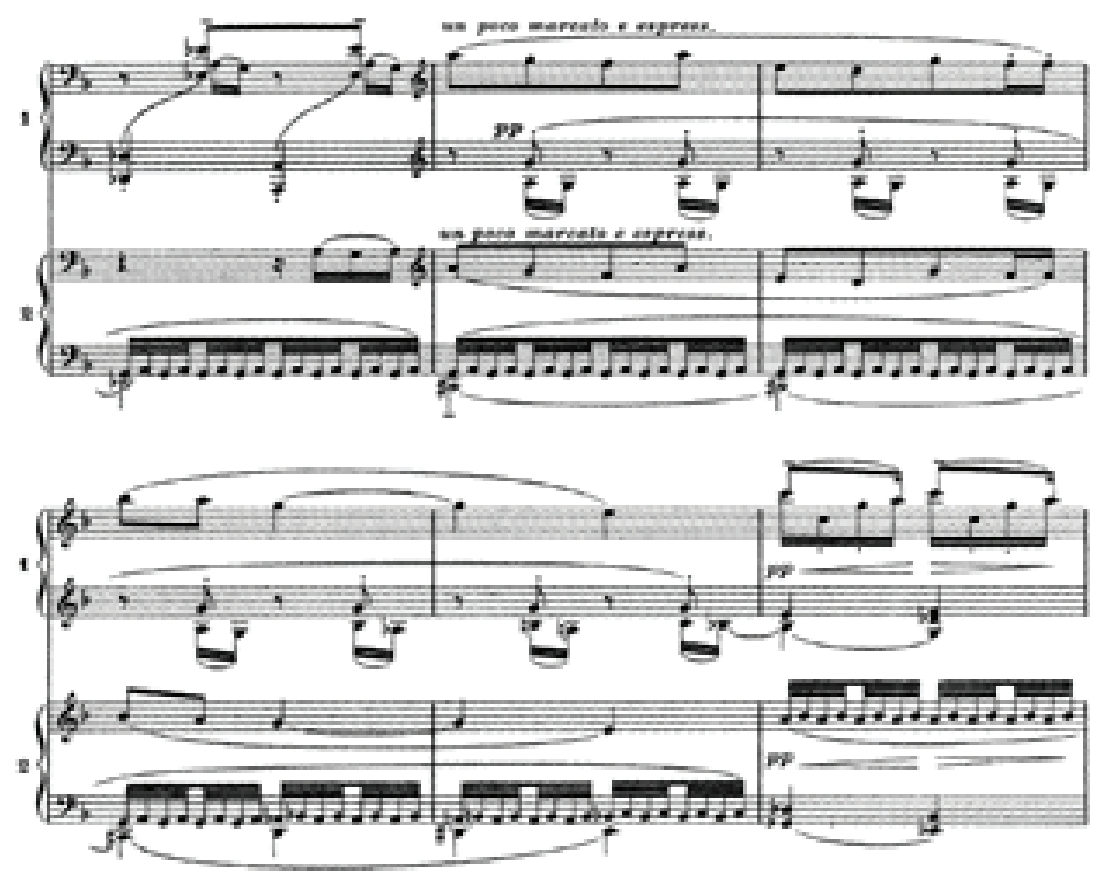

Figura 4: En blanc et noir, III, C.124-129. 
Possivelmente, a dissolução do material musical ao final da representa o inverno que termina cessando toda a sua agitação, o fim de seus ventos que darão lugar ao verão. Notamos ainda que é a única das três peças que termina dessa forma. As palavras de Debussy no final da obra são no mínimo curiosas, o verão deve ter despertado boas sensações no compositor e incitado o desejo de se expressar ao mundo:

Fin de "En blanc et noir" Eté 1915. (Fim de "Em branco e preto" Verão de 1915). Ver figura 5.

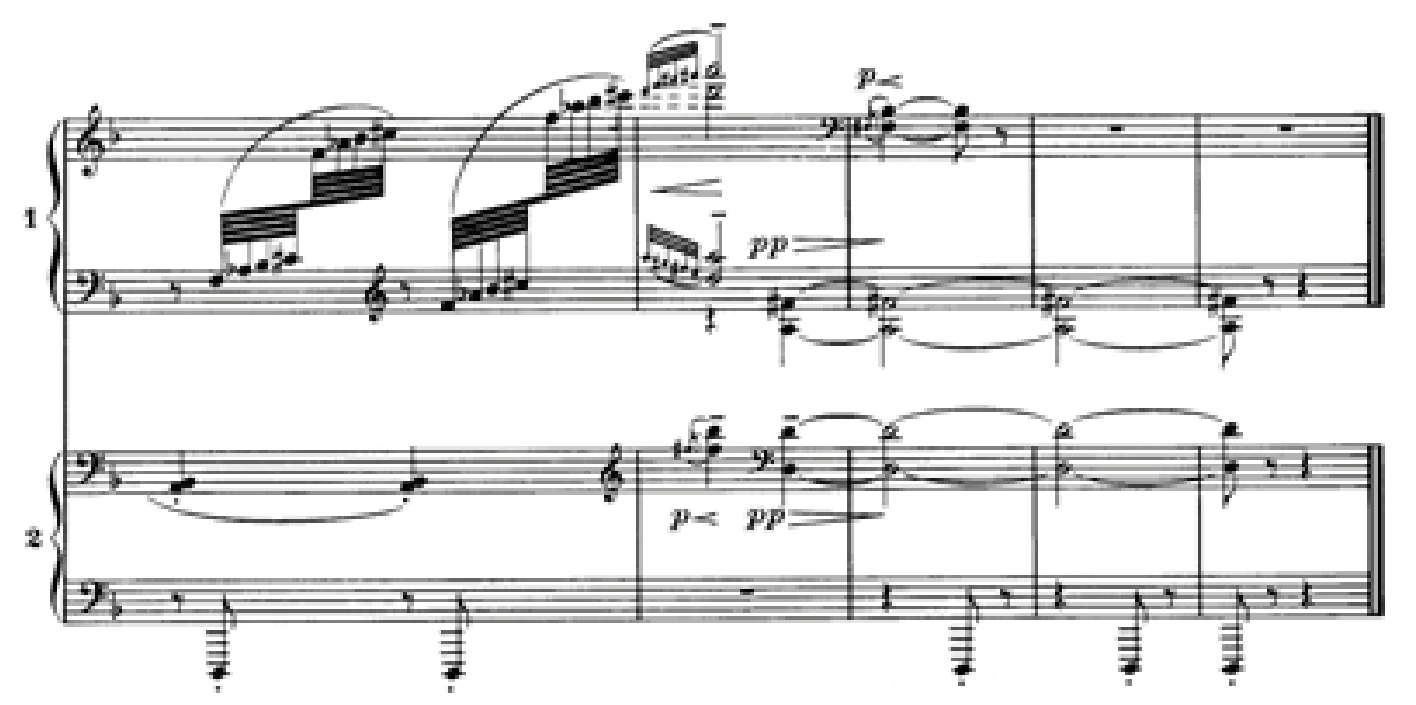

Fin de " $\mathrm{Bn}$ blane ef noir" vié sous.

Figura 5: En blanc et noir, III, última página.

\section{Entre os calos e o ímpeto nacionalista.}

Não é a toa podermos pensar no verão como um símbolo da revitalização artística: em julho de 1915 (verão no hemisfério norte) Debussy partiu com a família e passou três meses em Pourville, na Normandia, costa norte da França (como ele comenta com Stravinsky na carta), afastando-se dos problemas por um momento. A sua produção nesse período é impressionante: é nesse período de poucos meses que ele termina En blanc et noir, compõe os Doze Estudos para piano e duas das três sonatas, Sonata para Violoncelo e Piano e a Sonata para Flauta, Viola e Harpa. Esse ímpeto criativo surpreende, de alguma forma, até o próprio Debussy, que, 


\section{A Poética do Conflito na obra para dois pianos \\ En Blanc et Noir de Claude Debussy}

com perceptível animação, escreve a Bernardo Molinari (Regente muito aberto à música do seu tempo).

6 de outubro de 1915, Pourville.

Imagine, caro amigo, que eu fiquei quase um ano sem poder fazer música...Enfim eu precisei quase "reaprender" [termo usado por Debussy]. Foi para mim como uma descoberta, e ela [a música] me pareceu ainda mais bela! ${ }^{26}$

A guerra abalou bastante Debussy, que, conforme discutimos, passava também por seus próprios problemas pessoais. Desde o início do conflito até esses meses, ele quase não escrevera música, sua inquietude era grande e ele lamentava ter pouca força para lutar contra o inimigo que ameaçava seu país: "Chego a sentir inveja de Satie, que vai se ocupar seriamente da defesa de Paris como cabo". ${ }^{27} 0$ seu desejo de poder enfrentar também o seu inimigo iniciara quase um ano antes de se expressar com En blanc et noir, mas seu próprio desconforto não ficou fora da poesia dessa obra.

Setembro de 1914, a Jacques Durand.

(...) Precisamos lutar: tantos golpes sucessivos, tantos horrores revoltantes me cortam o coração. Eu não falo dos dois meses em que não escrevi uma nota, nem encostei no piano: é sem importância, na atual situação, eu sei bem; mas eu não posso me impedir de pensar com tristeza, na minha idade, que o tempo perdido é perdido para sempre. ${ }^{28}$

Na citada carta a Stravinsky ele também fala dos efeitos da guerra em sua produção comentando que havia "recuperado a faculdade do pensamento musical". Para avaliarmos como tudo isso se torna poesia na música vejamos a epígrafe da primeira peça:

Aquele que permanece em seu lugar

E não dança

De alguma desgraça

Faz, em silêncio, a confissão. ${ }^{29}$

Esse verso fala, a grosso modo, que há algo de errado com aquele que permanece em seu lugar e se recusa a dançar. Ele foi retirado do libreto de J. Barbier e M.

26 LESURE apud BENEDETTI, 2002a, p.62.

27 LESURE apud BENEDETTI, 2002a, p.54.

28 DURAND apud BENEDETTI, $2002 \mathrm{a}$, p.54.

29 Qui reste à sa place

Et ne danse pás

De quelquer disgrâce

Fait l'aveu tout bas. 


\section{A Poética do Conflito na obra para dois pianos \\ En Blanc et Noir de Claude Debussy}

Carré, da ópera Roméo et Juliette de Counod ${ }^{30}$. A fonte na quinta Cena do primeiro Ato do teatro de Shakespeare é clara. Capuleto recebe seus hóspedes para a festa:

Ah ha, minhas amantes! Qual de vocês todas

Irão agora se negar a dançar? Aquela que se faz muito mimosa,

Ela eu jurarei que possui calos.

0 anfitrião e seu primo, ambos da família Capulet discutem sobre o peso da idade, já que, para eles, os tempos de dança já passaram. Sobre a idade, Debussy sentia tristeza ao ver o tempo passar irremediavelmente.

ou melhor, sente-se bom primo Capulet,

Para você e eu passaram-se nosso dias de dança.

Quanto tempo faz desde que você e eu

Estávamos usando máscaras?

No fim da cena, Romeu, querendo saber quem era a donzela por quem se apaixonara, descobre: "Ela é da família Capulet? / Oh cara conta! Minha vida é dívida com meu inimigo." Julieta também questiona quem seria o cavalheiro que conhecera "0 que é aquele que segue lá, que não dança?" A resposta vem fulminante como um raio: "Seu nome é Romeo, e é um Montague, / 0 único filho de seu grande inimigo." Sua pergunta associa o homem que não dançou à desgraça: a paixão que entra em conflito com a rivalidade das famílias.

Debussy poderia estar se referindo a si próprio por possuir seus próprios calos e não poder dançar. Porém, porque ele cita Gounod e não Shakespeare diretamente? Dunsby mostra que Gounod era um símbolo de anti-germanismo que serviria ao propósito nacionalista do compositor. Em um artigo de suas críticas musicais Debussy explica porque a ópera insiste em tocar Fausto de Gounod:

Há muitas razões para isso, a melhor das quais é que a arte de Gounod representa um momento da sensibilidade francesa. Quer se queira ou não, essas coisas não se esquecem. (...)

Mesmo se Gounod não descreve a curva harmoniosa que se poderia desejar para ele, deve-se elogiá-lo por ter sabido escapar ao gênio imperioso de Wagner, cujo conceito bem alemão não justifica nitidamente o que ele quis de uma fusão das artes. ${ }^{31}$

Dunsby também encontra relação entre uma ária de Capuleto e o vigoroso tema do início dessa primeira peça de En blanc et noir como podemos verificar nas figuras 6 e 7. A similaridade não é totalmente clara, nós a percebemos em um excerto diferente do de Dunsby, acreditamos que o Fá\# é importante na percepção da relação pois se equipara à sensivel do final da frase musical da ária. De qualquer forma,

30 DUNSBY, 1996, p.166

31 DEBUSSY, 1889, p.171. Musica, julho de 1906. 'A Respeito de Charles Gounod'. 
essas referências são a maneira como o velho homem que "não pode mais dançar" ainda inicia seu capricho ostentando a bandeira de seu país, desafiadoramente ${ }^{32}$.

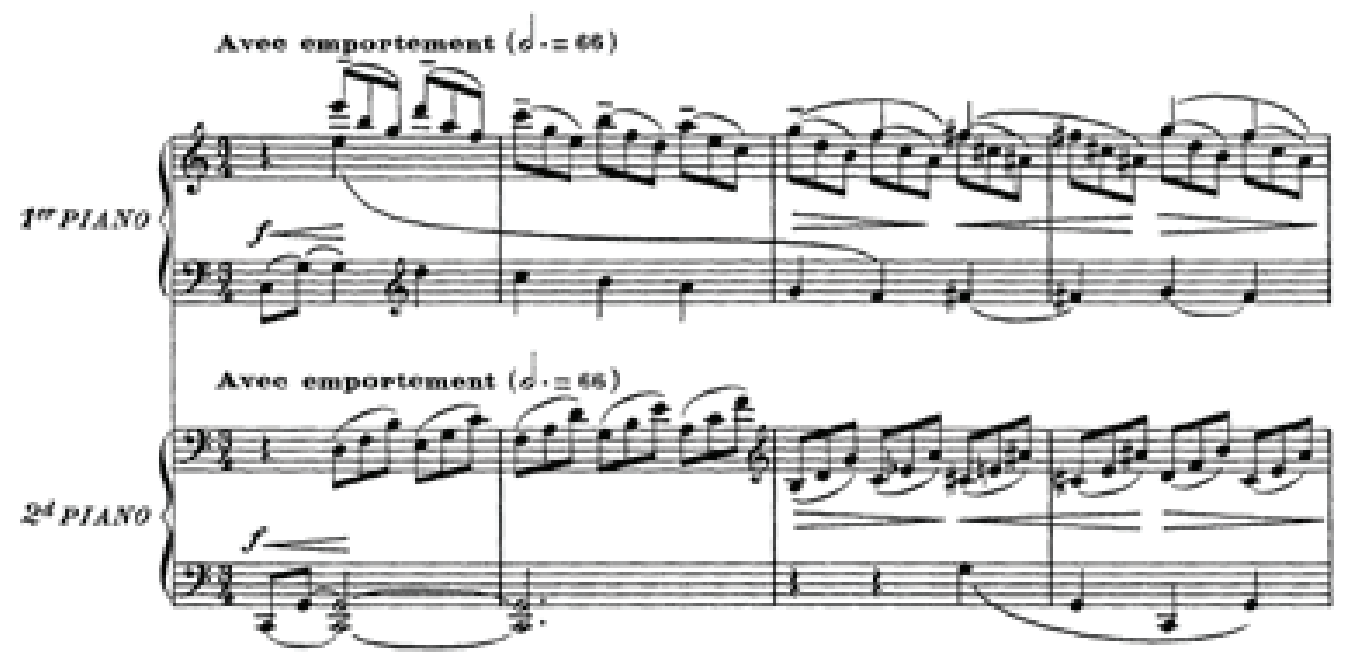

Fig.ura 6: En blanc et noir, I, C.1-4.

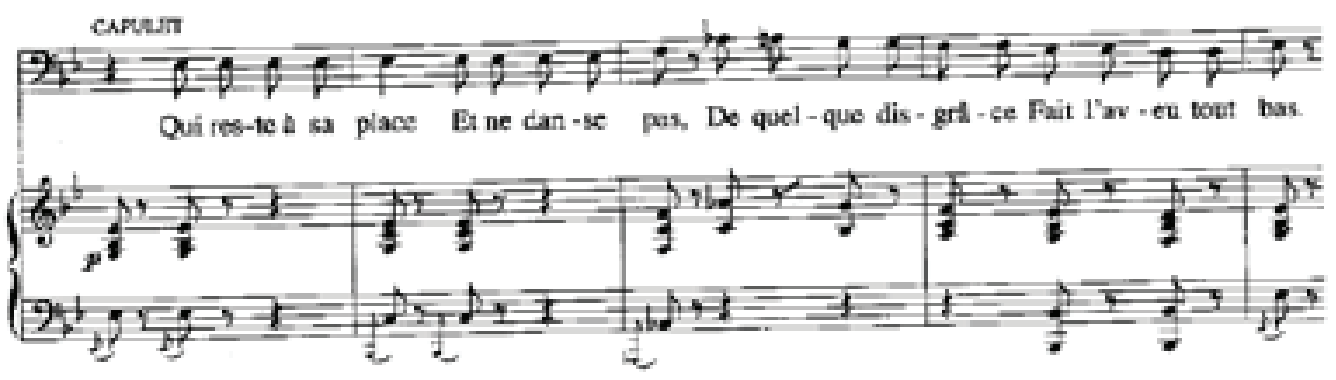

Fig.ura 7: Gounod, Roméo et Juliette, Capulet ária, vocal score p.28, C.1-5 (DUNSBY, 1996, p.167)33

Ainda nos intriga a dedicatória: à mon ami A. Kussewitsky, a qual Dunsby ignora e nenhuma das referências às quais tivemos acesso discorre sobre. A seguinte informação nos permite ter uma ideia do ele poderia estar querendo chamar a atenção sobre esse regente russo: no início de 1914, a convite de Kussewitsky, Debussy foi à Rússia reger suas obras em dois concertos de orquestra, um em São Petersburgo e outro em Moscou. No final das notas que Debussy envia a uma revista durante a viagem encontramos: "Tudo isso [aspectos de uma relação com a música], que é bonito, afirmo-lo, exige qualidades bem múltiplas. Elas se encontram reunidas na pessoa de S. Kussewitzky, cuja ardente boa vontade para servir à música não nos parece que vá conhecer novos obstáculos."34

32 DUNSBY, 1996, p.167-8.

33 Aria de Capulet em vídeo disponibilizado no site YouTube: http://www.youtube.com/watch?v=LRKphh1vEdM

34 DEBUSSY, 1989, p.221. S.I.M., 1Ć de Janeiro de 1914. 'Concertos Colonne.' É curioso que as 


\section{A Poética do Conflito na obra para dois pianos \\ En Blanc et Noir de Claude Debussy}

Debussy não previra que a Primeira Guerra Mundial, ao escrever pouco antes de seu início, tornaria necessário para Alexandrovich Kussewitsky limitar suas atividades. ${ }^{35}$ Nessa dedicatória ele pode também estar lamentando a influência da guerra no trabalho desse colega, que por causa dela poderia também estar "sem dançar".

\section{Que o vento dissolva os nocivos gases da guerra}

Terminemos nossa coleção de referências poéticas adentrando nas sombras do capricho que encara a guerra como temática abordada. Sua natureza como conflito dispensa apresentações e os elementos presentes nessa peça são fortes. Para a epígrafe foi escolhido um poema de François Villon (provavelmente nascido em 1431 e o último registro de que estava vivo é de 1463) que é aproximadamente contemporâneo do século XV de Charles d'Orléans. A composição Trois Ballades de François Villon de 1910 (o poema escolhido para a epígrafe não faz parte dessas canções) é um dos indícios de que Debussy parecia cultivar uma relação com esse poeta: em uma carta de 1913 para o amigo Pierre Louÿs ele escreve "Diga o que você quiser, um volume de Villon é mais útil que uma bengala!" após receber um livro de presente do acervo pessoal de Louÿs; ou então, uma descrição do estúdio de Debussy36:

Tudo ali dentro era cuidadosamente selecionado e refinado. Apesar do fato de que ele era um homem de ampla leitura, os livros dentro do seu estúdio não eram mais numerosos que cem, e aqueles eram somente autores que Debussy tinha escolhido como seus favoritos particurales Rossetti, Maeterlinck, uma edição antiga de François Villon, Mallarmé. ${ }^{37}$

Apesar dos especialistas discutirem, Villon tem sido chamado o maior poeta lírico da França, e recebeu muita atenção nos quinhentos anos que se passaram: somente 0 século XVII não viu novas edições das poesias de Villon ${ }^{38}$. A epígrafe cita a última estrofe, o 'envoi'39, da Ballada contre les ennemis de la France:

interpretações de Kussewitsky sobre as obras de Debussy tenham se tornado muito notáveis.

35 BAKER'S STUDENT ENCYCLOPEDIA OF MUSIC. “Koussevitzky (Kussevitsky), Serge

(Alexandrovich)". Ed. Laura Kuhn. Schirmer-Thomson Gale, 1999. eNotes.com, 2006. Disponível em <http://www.enotes.com/music-encyclopedia/

koussevitzky-kussevitsky-serge-alexandrovich〉 Acesso em: 14 jun. 2011.

36 DUNSBY, 1996, p.160.

37 E. Robert Schmitz, 'A Plea for the Real Debussy', re-impresso em Debussy Remembered, ed. Roger Nichols, p. 168.

38 DUNSBY, 1996, p.158.

39 Um envoi é uma estrofe curta no final cuja função primeira era a de concentrar em poucos versos toda a matéria do poema. Na balada tradicional, é comum encontrar este tipo de remate de uma composição poética, normalmente dedicado ao elogio de um nobre ou de uma figura 


\title{
A Poética do Conflito na obra para dois pianos \\ En Blanc et Noir de Claude Debussy
}

\author{
Príncipe, levado seja pelos servos de Aeolus \\ Para a floresta onde reina Glaucus \\ Ou privado seja de paz e esperança \\ Pois não é digno de possuir virtudes \\ Quem mal desejar ao reino da França..$^{40}$
}

'Prince' diz respeito a uma convenção do estilo, 'serfs de Eolus' significam o vento, pois esse era o governante dos ventos na mitologia greco-romana, assim como, na segunda estrofe, acredita-se que seja uma referência ao mar. Ou então, entre todas as calamidades que poderiam acontecer aos inimigos do Reino da França, que sejam privados de virtudes. ${ }^{41} \mathrm{~A}$ dedicatória aqui, feita au Lieutenant Jacques Charlot tué à l'ennemi en 1915, le 3 Mars (ao Tenente Jacques Charlot morto pelo inimigo em 3 de Março de 1915), sobrinho do seu editor Jacques Durand, torna essa peça carregada e lúgubre, nos ajuda entender o motivo da força direcionada contra o inimigo através desse poema escolhido - além de todo o ranço a inimiga Alemanha já citado.

Também fazem parte desse capricho, que apresenta um ponto de vista do "músico francês" sobre a guerra, referências musicais que Debussy anuncia em carta:

22 de julho de 1915, a Jacques Durand.

Você verá o que pode acontecer ao hino de Lutero por ter imprudentemente penetrado num Caprice à francesa. Quase no fim, um modesto carrilhão faz soar uma pré-Marselhesa. Mesmo desculpando-se deste anacronismo, isto é admissivel numa época em que os pavimentos das ruas $e$ as árvores das florestas estão vibrantes deste canto onipresente. ${ }^{42}$

0 hino referido é "Ein feste Burg ist unser Cott" (Castelo forte é o nosso Deus) em sua versão mais popular (ver Fig.8). Ele possui forte associação a batalha da reforma protestante e é um dos preferidos dentro dessa tradição. Foi bastante utilizado na literatura musical, por isso pode se esperar que os contemporâneos europeus, independentemente de serem luteranos, o reconhecessem facilmente na música: Johann Sebastian Bach utilizou sua melodia como tema da Cantata BWV 80; Felix Mendelssohn empregou-a no último movimento da sua 5 š sinfonia (Sinfonia da Reforma); na ópera "Os Huguenotes" de Giacomo Meyerbeer, é utilizada diversas

heróica. DRAGONET apud CEIA, Carlos. E-Dicionário de Termos Literários. Disponível em <http:// www.edtl.com.pt/index.php?option=com_mtreectask=viewlinkđllink_id=983Сtltemid=2>Acesso em: 10 de jun. 2011.

40 Prince, porte soit des serfs Eolus

En la forest ou domine Glaucus.

Ou Privé doi te paix et d'espérance

Car digne n'est de posséder vertus

qui mal Voldroit ou royaume de France.

41 DUNSBY, 1996, pp.163-4.

42 DURAND apud BENEDETTI, 2002, p.68. 
vezes como Leitmotiv; é também citada na ópera "Friedenstag", de Richard Strauss. ${ }^{43}$

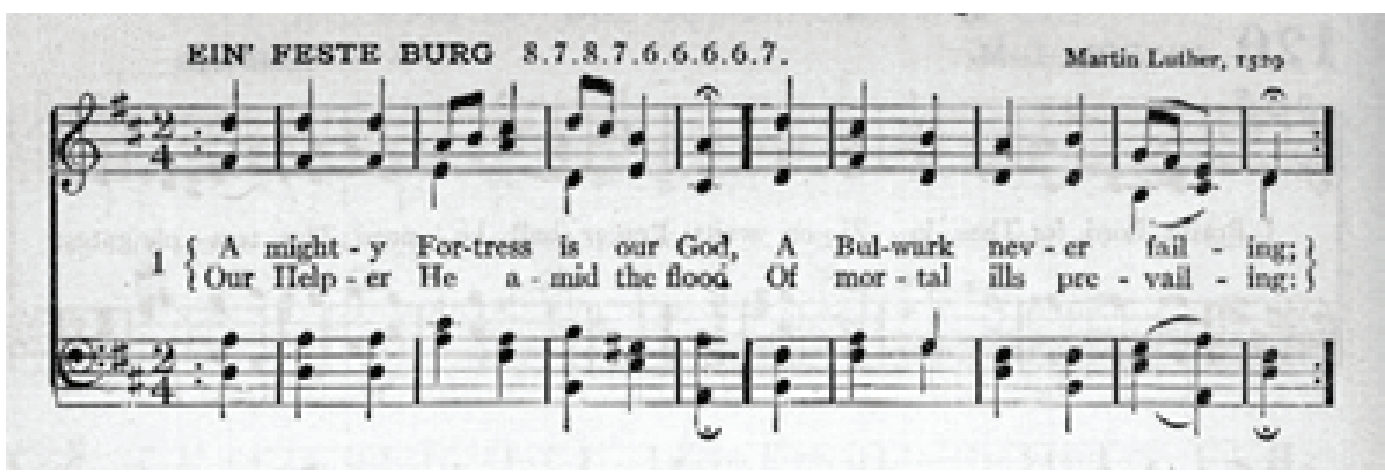

Fig.ura 8: Hino Ein feste Burg ist unser Gott. ${ }^{44}$
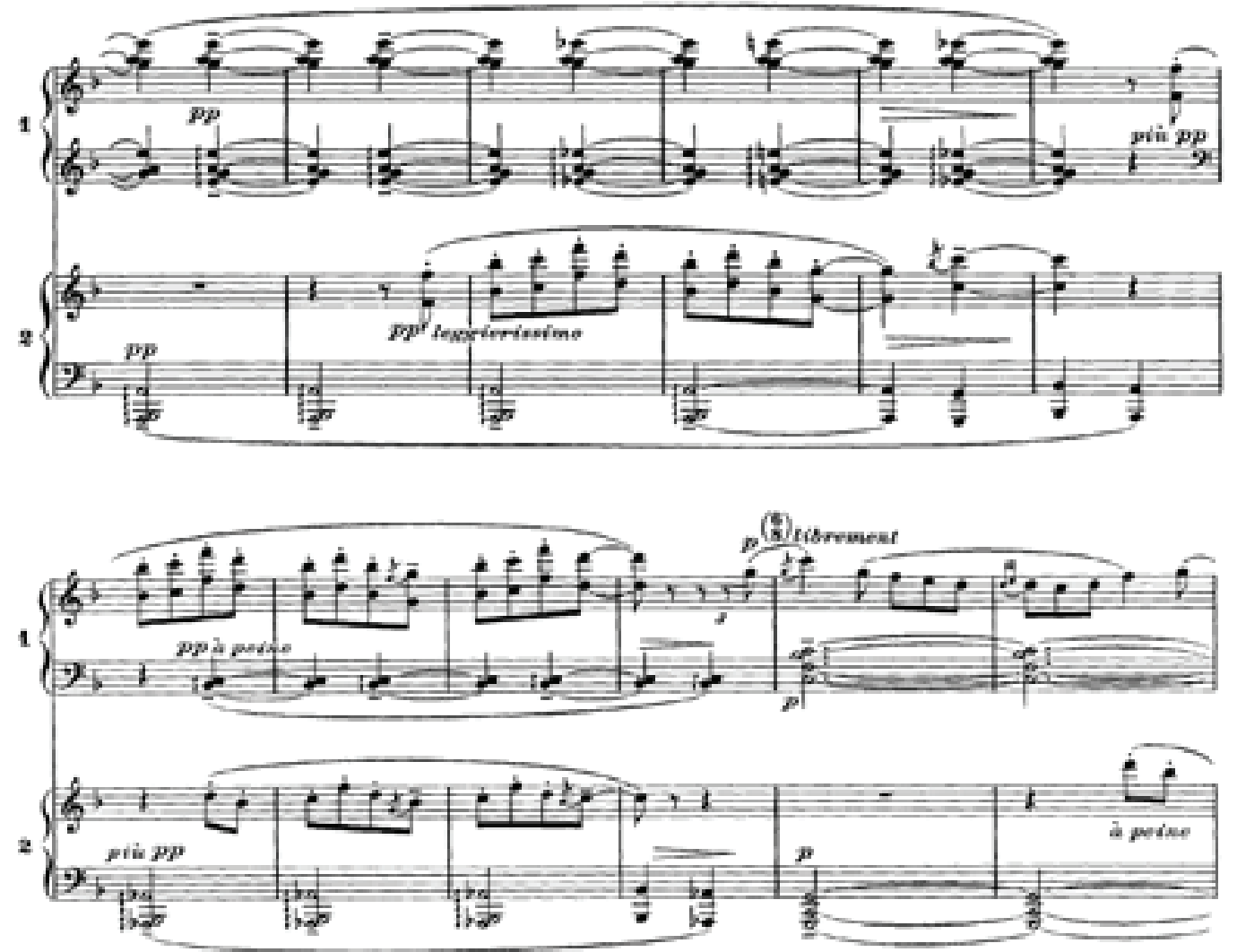

Figura 9: En blanc et noir, II, C.161-172.

Apesar de ele ter dado todas as pistas necessárias, a pré-Marselhesa pode causar

43 Essas informações estão amplamente disponíveis na internet, como no artigo da enciclopédia virtual Wikipédia sobre o assunto.

44 Domínio público. Disponível em <http://pt.wikipedia.org/wiki/Ficheiro:Luther\%27s_A_Mighty_ Fortress_isorythmic.jpg> acesso em: 15 de jun. 2011. 


\section{A Poética do Conflito na obra para dois pianos \\ En Blanc et Noir de Claude Debussy}

mais dúvida para saber a que trecho o compositor estava se referindo. Dunsby $(p .164)$ escreve em nota que sempre considerou um trecho em torno do compasso 140, mas que para concordância geral a melodia não foi encontrada. Para nós, porém, fica clara a referência à penúltima página quando ele diz: "quase no fim, um modesto carrilhão faz soar". A textura em oitavas reverberando no segundo piano e uma interpretação adequada da articulação revela o dobrar de sinos esboçando uma melodia claramente associável à da Marselhesa (figura 9).

Encerramos nosso trabalho com uma última referência que contribui para atmosfera bélica dessa peça. É um toque de clarim, que se assimila muito ao toque de cavalaria e artilharia francesa ${ }^{45}$. Ele foi inserido pelo compositor em diversos momentos na música a partir do início, incluindo um material que encerra o segundo movimento.

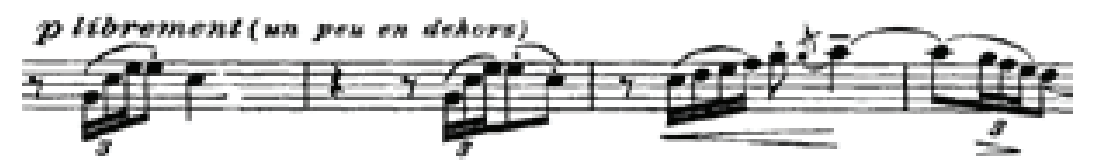

Figura 10: En blanc et noir, II, C.7-10. Toque de clarim.

Assim, essas informações sobre a poética de En blanc et noir nos permitem ver essa música como uma fantasia (capricho) sobre a temática dos conflitos que afetavam Debussy no início do séc. XX. Desse modo, atribui-se um conteúdo muito significativo a essa obra, a partir de uma relação de significados subjetivos. Considerá-lo um poeta permite reconhecer uma dimensão de sua música que revela a flexibilidade e a liberdade de sua técnica composicional. Entender a carga expressiva que sua música transporta, a partir de tudo que a ela está relacionado, pode conferir grande riqueza à interpretação dessa construção musical extremamente refinada.

45 LAROUSSE UNIVERSEL. Tome Premier. Publié sous la Direction de Claude Augé. Paris: Librairie Larousse, 1922. P.103. 


\section{Referências Bibliográficas}

> BENEDETTI, Danieli. A Produção Pianística de Claude Debussy durante a Primeira Guerra Mundial. Dissertação de Mestrado em Música. São Paulo: ECA/USP, 2002a. $>$. A Produção Pianística de Claude Debussy durante a Primeira Guerra Mundial. Anais de Fórum CLM 2002. São Paulo: ECA/USP, 2002b, pp. 108-116. Claude Debussy e o ano de 1915. Anais do XVI Congresso da Associação Nacional de Pesquisa e Pós-graduação em Música (ANPPOM). Brasília, 2006. pp. $958-963$.

> CEIA, Carlos. E-Dicionário de Termos Literários. Disponível em <http://www. edtl.com.pt/index.php?option=com_mtreecttask=viewlinkCAlink_id=983Clttemid=2> Acesso em: 10 de jun. 2011.

> CRAFT, R.; STRAVINSKI, I. Conversas com Igor Stravinski. São Paulo: Perspectiva, 1984.

$>$ DUNSBY, Jonathan. The Poetry of Debussy's En blanc et noir. In: Analytucal Strategies an Musical Interpretation. Editapo por Craig Ayrey and Mark Everist. Cambridge: Cambridge University Press, 1996. Pp. 149-68.

$>$ DEBUSSY, Claude. En blanc et noir. Paris: Durand et Cie., 1915. Disponível em 〈http://imslp.org/wiki/En_blanc_et_noir_(Debussy,_Claude)> Acesso em: 14 de jun. 2011.

> DEBUSSY, Claude. Monsieur Croche e outros ensaios sobre música. Tradução de Raquel Ramalhete. Rio de Janeiro: Nova Fronteira, 1989.

> DEBUSSY, Claude. Préludes pour piano: ....Le vent dans la plaine. Paris: Durand it Cie., 1910. Pp.7-12. Disponível em <http://imslp.org/wiki/Pr\%C3\%Agludes_ (Book_1)_(Debussy,_Claude)> Acesso em: 14 de jun. 2011.

> BAKER'S STUDENT ENCYCLOPEDIA OF MUSIC. "Koussevitzky (Kussevitsky), Serge (Alexandrovich)". Ed. Laura Kuhn. Schirmer-Thomson Gale, 1999. eNotes.com, 2006. Disponível em <http://www.enotes.com/music-encyclopedia/koussevitzkykussevitsky-serge-alexandrovich> Acesso em: 14 jun. 2011.

> LAROUSSE UNIVERSEL. Tome Premier. Publié sous la Direction de Claude Augé. Paris: Librairie Larousse, 1922.

> MARTINS, Jose Eduardo. 0 Som Pianístico de Claude Debussy. São Paulo: Novas Mestas, 1982.

> NICHOLS, Roger. Debussy Remembered. Portland, Oregon: Amadeus Press, 1992.

> PAULIN, Scott D. "Cinematic" Music: Analogies, Fallacies, and the Case of Debussy. In: Music and the Moving Image, University of Illinois Press, v.3, n.1, spring 2010. Pp. 1-21. 
A Poética do Conflito na obra para dois pianos

En Blanc et Noir de Claude Debussy

Menan Medeiros Duwe, UDESC - Graduando do Bacharelado em Música.

menan.md@gmail.com

Prof. Dr. Guilherme Antonio Sauerbronn de Barros, UDESC - Professor do curso de graduação e pós-graduação em música.

guisauer@gmail.com 